\title{
WAVE STATISTICS AND SPECTRAL ANALYSIS \\ IN THE MEDITERRANEAN SEA (i.e. SICILY CHANNEL): \\ 9 YEARS OF WAVE DATA MONITORING \\ by \\ TERRILE ${ }^{1}$ E., DE FILIPPI ${ }^{1}$ G. and SPADACCINI ${ }^{2} O$.
}

\section{GOALS}

Monitoring of the VEGA-A oil-platform, as required by EDISON ;

- Define and characterize the wave field in the Mediterranean Sea, i.e. Sicily channel.

\section{INTRODUCTION}

Even if it is not always the appropriate wave spectrum, the JONSWAP spectrum is often used in the Mediterranean Sea as input for the most common $3^{\text {rd }}$-generation spectral wave models. The definition of site-specific spectral parameters by means of measured wave data allows to get a better assessment of the wave field in the coastal area with consequent better description of the wave characteristics to be used as design basis for coastal structures.

\section{VEGA-A OIL-PLATFORM and METOCEAN study}

VEGA-A is the largest oil-platform in the Mediterranean Sea, Sicily channel, $~ 20 \mathrm{~km}$ far from the coast; EDISON has been actively supporting along the years the whole monitoring system at VEGA-A.
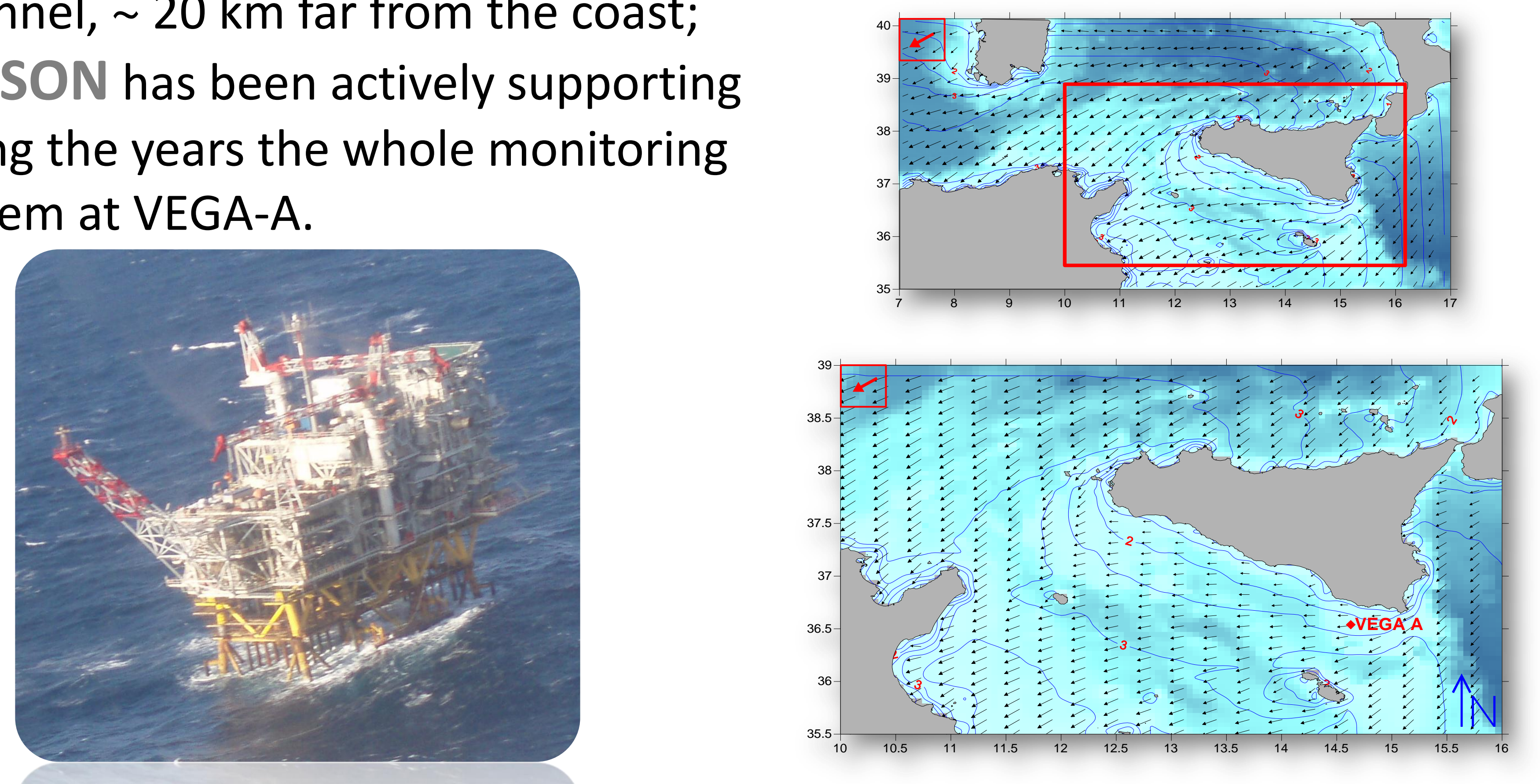

\section{MONITORING SYSTEM}

Ad hoc Monitoring System for VEGA-A location build-up by

DEAM on the basis of the metocean analysis, as required by EDISON

Simultaneous measures of Pressure and orbital wave Velocities ( $\mathrm{x}$ - and $y$ - directions)

RAW DATA Sampling Frequency: $2 \mathrm{~Hz}$

As usually done in oceanography every single raw data is recorded in $20 \mathrm{~min}$, i.e.1024 s, to get 2048 records.

\section{WAVE DATA ANALYSIS}

Selection of raw data for storms with $\mathrm{Hs}>3.5 \mathrm{~m}$

A total of 16 storms in 9 years

(2002-2010)

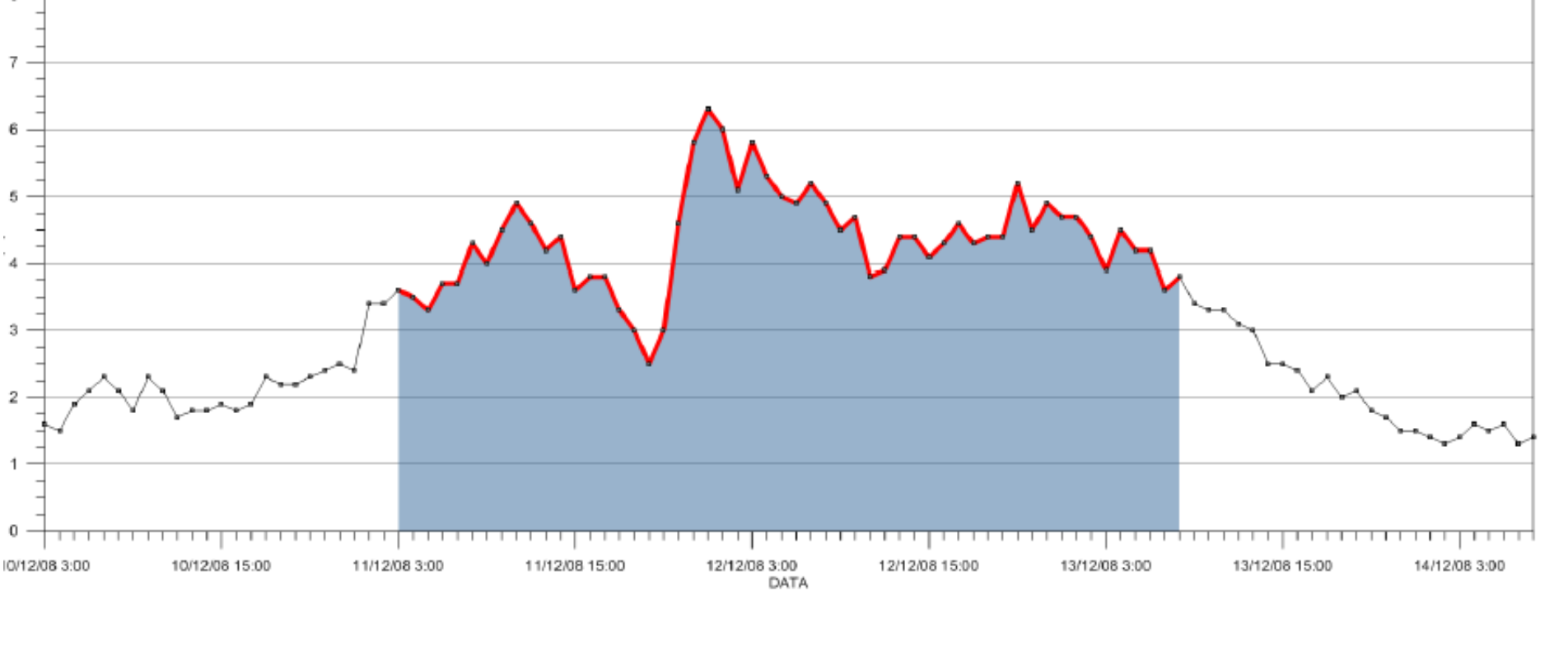

\section{Orbital Velocities}

water level raw data orbital velocity EAST components orbital velocity NORTH components

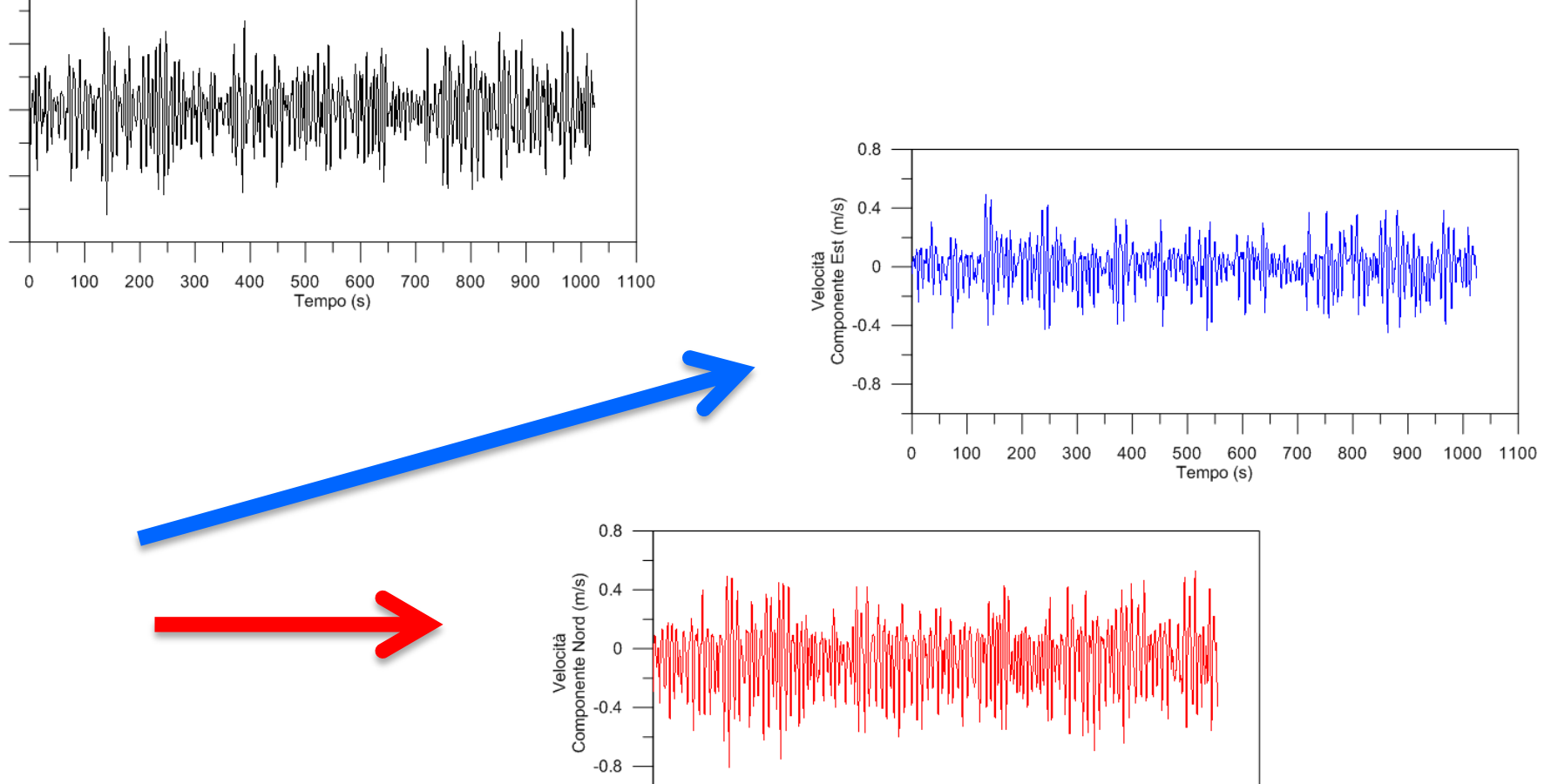

Measured data vs classical Stokes IV order theory

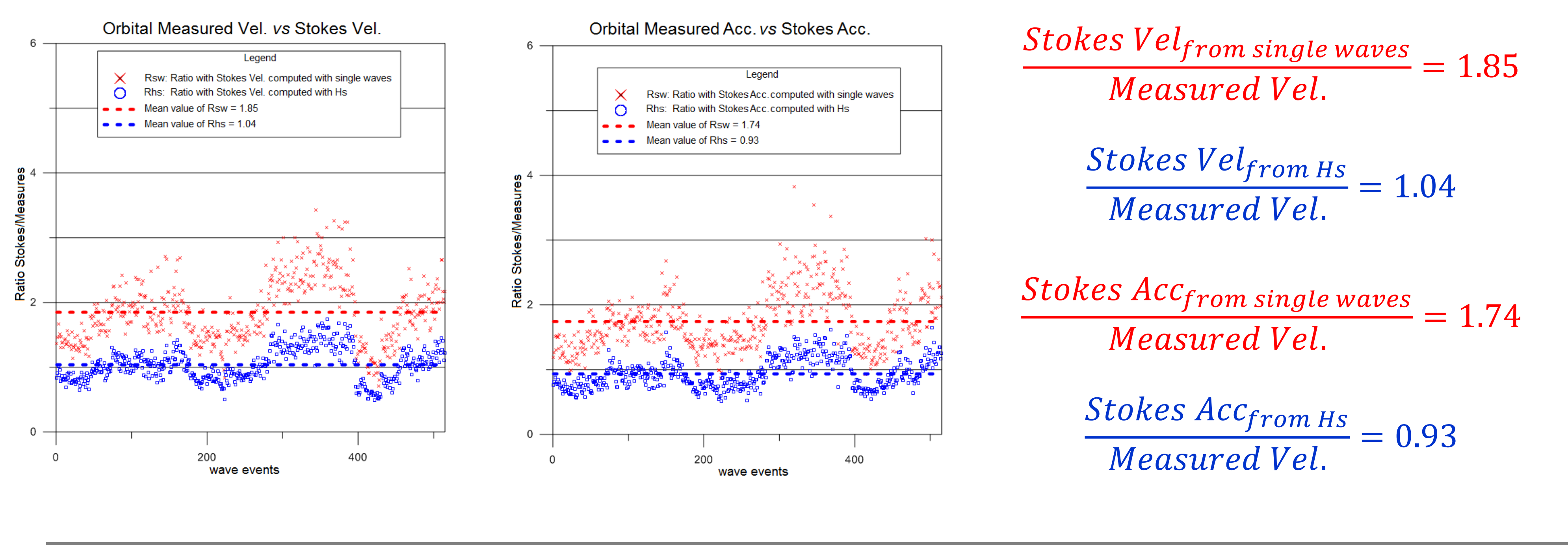

Spectral Analysis

FFT (Fast Fourier Transformation) Method

Proposed JONSWAP parameters - fitting

$\gamma=0.1783 \exp \left(1.352+0.2225 \frac{T_{p}}{\sqrt{H_{s}}}\right)$ valid for $\frac{T_{p}}{\sqrt{H_{s}}}>4.2$

For $f<f_{p}$

Ga mean value $=0.152$

For $f>f_{p}$

$\sigma_{b}$ mean value $=0.111$

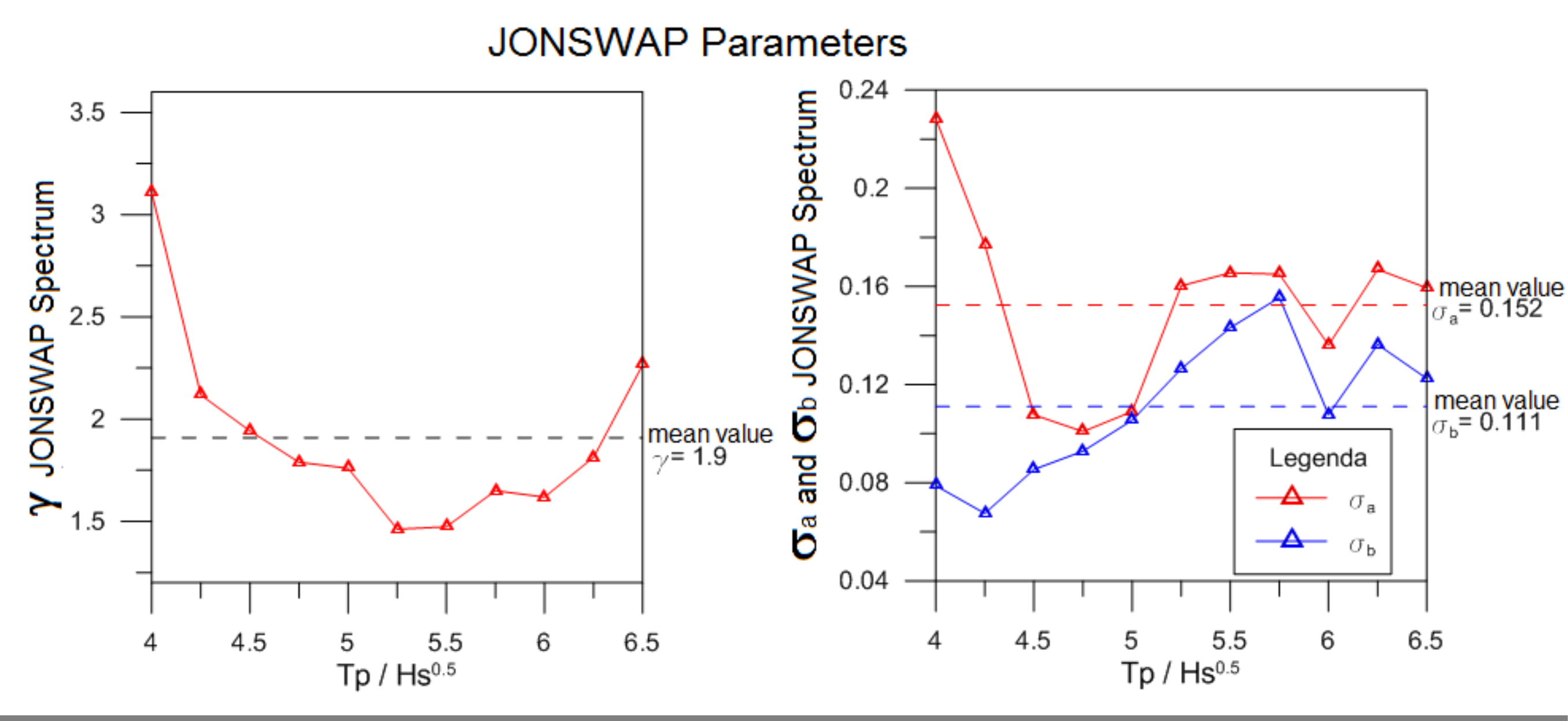

Single Wave Analysis

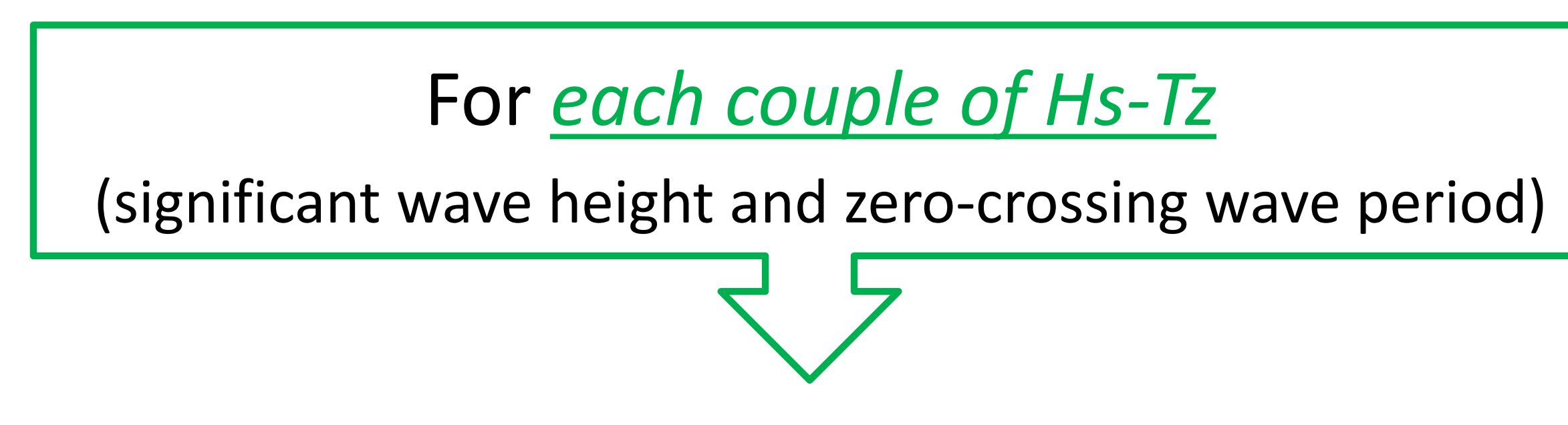

number of couple H-T

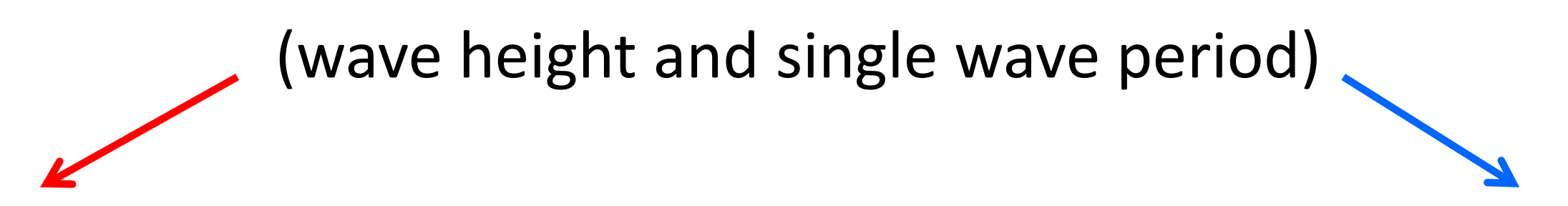

Measured in raw data

Theory, i.e.Cavanié et al. 1976

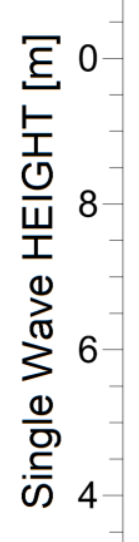
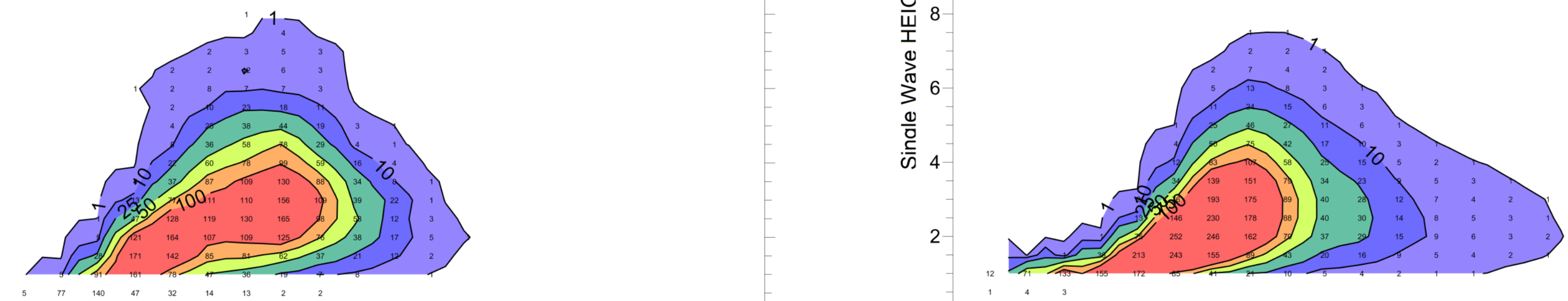

REFERENCES

Cavanié, Arhan, and Ezraty, 1976. A statistical relationships between individual heights and periods of storm waves. $5^{\text {th }}$ SPE Int.Conf. Stavenger, Norway

\section{AKNOWLEDGEMENTS}

The authors wish to acknowledge EDISON for supporting actively the metocean monitoring system and for allowing the use of the collected metocean data.

\section{DEAM}

